\title{
Carotid artery cannulation in aortic surgery
}

\author{
Paul P. Urbanski, MD, ${ }^{a}$ Aristidis Lenos, MD, ${ }^{a}$ Yvonne Lindemann, MD, ${ }^{a}$ Ernst Weigang, MD, ${ }^{\text {b }}$ Michael Zacher, MD, \\ and Anno Diegeler, $\mathrm{MD}^{\mathrm{a}}$
}

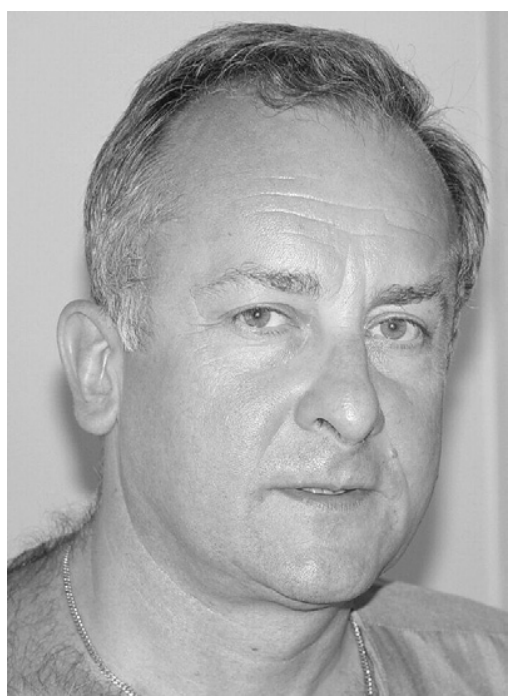

Dr Urbanski
Objective: Carotid artery cannulation was initially established at our clinic for surgery of acute aortic dissection, and it became the standard approach for procedures in which circulatory arrest is necessary. The aim of the study was to evaluate this method's efficiency regarding postoperative outcomes after the first 100 procedures.

Methods: Between July 2002 and October 2005, 100 patients underwent aortic surgery using carotid artery cannulation by a side graft for arterial return with a mean flow rate of $4.6 \pm 0.5 \mathrm{~L} / \mathrm{min}$. There were 27 patients with acute and 2 with chronic type A aortic dissection. Sixteen patients had had prior cardiac surgery. During circulatory arrest, the arterial line was used for unilateral cerebral perfusion in moderate hypothermia (mean rectal temperature $28^{\circ} \mathrm{C} \pm 1.6^{\circ} \mathrm{C}$ ) with a mean flow rate of $0.85 \pm 0.2 \mathrm{~L} / \mathrm{min}$.

Results: Carotid artery cannulation offered adequate arterial return in all patients. In no case was a switch to another cannulation site necessary for arterial return. Furthermore, no complications related to the cannulation site were observed. One patient with acute dissection and 1 with chronic aneurysm died during the early postoperative course. Thus, 30-day mortality was $2.0 \%$ for the whole group and $3.7 \%$ for the dissection group. Two patients with severe calcification of the aortic valve had strokes. There were no strokes in the dissection group, although there were preoperative signs of cerebral malperfusion in 4 patients.

Conclusions: Carotid artery cannulation is a fast, safe, and efficient method of arterial cannulation even in very obese patients. In addition, it simplifies the procedure of unilateral cerebral perfusion through the arterial line during circulatory arrest, making it completely unnecessary to interrupt cerebral perfusion.

\footnotetext{
From the Department of Cardiovascular Surgery, Cardiovascular Clinic Bad Neustadt, Bad Neustadt, Germany, ${ }^{\mathrm{a}}$ and the Department of Cardiovascular Surgery, University Hospital Freiburg, Freiburg, Germany. ${ }^{\mathrm{b}}$

Read at the Eighty-sixth Annual Meeting of The American Association for Thoracic Surgery, Philadelphia, Pa, April 29-May 3, 2006.

Received for publication April 19, 2006; revisions received July 7, 2006; accepted for publication July 12, 2006.

Address for reprints: Paul Urbanski, MD, Herz- und Gefaess-Klinik, Salzburger Leite 1, 97616 Bad Neustadt, Germany (E-mail: p.urbanski@kardiochirurg.de).

J Thorac Cardiovasc Surg 2006;132:1398-403 $0022-5223 / \$ 32.00$

Copyright $(9) 2006$ by The American Association for Thoracic Surgery

doi:10.1016/j.jtcvs.2006.07.024
}

$\mathrm{T}$ here are two methods for cerebral protection in cardiovascular surgery requiring circulatory arrest: deep hypothermia, which may also be complemented by retrograde cerebral perfusion $(\mathrm{CP})$, and selective antegrade $\mathrm{CP}$. Because the choice of cannulation site in the first method does not seem to play a role, ${ }^{1-3}$ the cannulation of one arch artery in the second method results in an antegrade perfusion of the aorta and, in particular, in simplified handling of antegrade CP for which brain perfusion need not be interrupted. Meanwhile, cannulation of the axillary artery for arterial return and for $\mathrm{CP}$ is a well-established method., ${ }^{4,5}$

Initially, the carotid artery was only cannulated to establish an additional arterial line for $\mathrm{CP}$, mainly in connection with the second line in the femoral artery. ${ }_{6}^{6,7}$ However, single cannulation of the carotid artery is also a simple and safe approach for arterial return during cardiopulmonary bypass $(\mathrm{CPB}) .{ }^{8,9}$ The aim of this study was to evaluate this technique's clinical usefulness and efficiency in terms of postoperative and particularly neurologic outcomes after the first 100 procedures.

\section{Patients and Methods}

Between July 2002 and October 2005, 100 patients underwent surgery with carotid artery cannulation in our facility for the treatment of thoracic aortic disease. There were three stages 


\section{Abbreviations and Acronyms \\ $\mathrm{CP}=$ cerebral perfusion \\ $\mathrm{CPB}=$ cardiopulmonary bypass \\ $\mathrm{CT}=$ computed tomography}

of patient selection for use of this surgical technique; however, all perioperative data were acquired prospectively. Initially, the carotid artery was cannulated exclusively in patients with acute aortic dissection. In the second stage, the selection was extended to elective patients at high surgical risk presenting a vital indication for surgery. This can explain the very high average EuroSCOREs in our series. Since 2005 this cannulation technique has been used in all patients who have undergone aortic surgery requiring circulatory arrest. Informed consent for the operations was obtained from all conscious patients.

The main indication for surgery in this series was chronic degenerative or atherosclerotic aneurysm followed by aortic dissection. Detailed information on aortic disease is presented in Table 1, and the preoperative patient data are given in Table 2.

The arterial return for CPB was achieved by isolated cannulation of the carotid artery in 86 patients and by simultaneous carotid and femoral cannulation with a Y-shaped tube in 14 patients. The only criteria for additional cannulation of the femoral artery were stenosis or compression of the true lumen in the proximal part of the carotid artery, which might adversely affect the rest of the body's perfusion, or very complex surgery of the thoracic aorta for which protracted circulatory arrest would be expected. The decision was made preoperatively on the basis of computed tomography (CT), which was performed on all patients and comprised scans of the chest, abdomen, and middle neck areas. Additional diagnostics such as neurovascular examination, including Doppler ultrasonography of the extracranial vessels and, when feasible, transcranial Doppler ultrasonography were only performed on elective patients. Moreover, cranial CT angiography was carried out to evaluate the circle of Willis. Cerebral monitoring tools included arterial pressure lines in radial arteries and, in elective patients, electroencephalogram, measurement of somatosensory evoked potentials, and transcranial Doppler ultrasonography of the middle cerebral arteries, if feasible.

TABLE 1. Aortic disease

\begin{tabular}{lc}
\hline Type & No. \\
\hline Chronic true aneurysm* $^{*}$ & 62 \\
Acute type A aortic dissection & 27 \\
Chronic type A dissectiont & 2 \\
False aneurysm $\ddagger$ & 3 \\
Porcelain aorta & 4 \\
Hypoplastic arch & 2 \\
\hline
\end{tabular}

*Including leaking arch aneurysm in 1 case. $†$ After ascending replacement. $\ddagger$ After aortic valved conduit replacement in 2 patients and coronary artery bypass grafting in 1 patient.
TABLE 2. Preoperative patient characteristics

\begin{tabular}{lc}
\hline Age (y) & $64 \pm 13(14-84)$ \\
Male/female & $64 / 36$ \\
Functional class NYHA III or IV & 53 \\
Previous cardiac surgery & 16 \\
Aortic valve replacement/repair & 11 \\
$\quad$ Coronary artery bypass grafting & 6 \\
$\quad$ Ascending aortic replacement & 4 \\
Concomitant diseases & \\
$\quad$ Hypertension & 85 \\
Coronary heart disease & 35 \\
Chronic obstructive pulmonary & 16 \\
$\quad$ disease & \\
Previous neurologic events & 5 \\
Neurologic status & \\
$\quad$ Intubated, unconscious & 4 \\
Somnolent, unresponsive & 5 \\
Malperfusion & \\
$\quad$ Cerebral & \\
Spinal & \\
Visceral & \\
Peripheral & 2 \\
Logistic EuroSCORE & 2 \\
&
\end{tabular}

Data are expressed as number of occurrences or as mean number \pm SD (range). NYHA, New York Heart Association class.

\section{Surgical Technique}

The thoracic aorta and heart were exposed via median sternotomy in 96 patients, including a left lateral extension in 1 patient and clamshell thoracotomy in 4 patients. The carotid artery cannulation technique has been described previously. $^{3}$ In short, the left carotid artery was isolated intrathoracically up to a length of 3 to $4 \mathrm{~cm}$ in 30 patients. The left (69) or right (1) carotid artery was prepared in 70 patients through a separate skin incision in the neck along the medial margin of the sternocleidomastoid muscle.

In all patients, after heparinization, the exposed segment of the carotid artery was crossclamped, a longitudinal incision was made, and an 8- or 10-mm vascular sealed polyester graft was anastomosed to the artery with a continuous 5-0 polypropylene suture. If additional cannulation of the femoral artery was considered necessary, it was done simultaneously in the usual manner, and both arterial lines were connected with a Y-shaped tube for arterial return from one pump.

After connection of the arterial line and cannulation of the right atrium, CPB was started with a mean flow of $4.6 \pm$ $0.5 \mathrm{~L} / \mathrm{min}$, range 3.6 to $6.0 \mathrm{~L} / \mathrm{min}\left(2.4 \mathrm{~L} \cdot \mathrm{min}^{-} 1 \cdot \mathrm{m}^{-2}\right.$ of body surface). The perfusion pressure at the arterial line was limited to not more than $260 \mathrm{~mm} \mathrm{Hg}$ and amounted to 200 $\pm 27 \mathrm{~mm} \mathrm{Hg}$ on average.

In all but 2 patients, circulatory arrest for arch repair was necessary. The arch arteries were crossclamped and unilateral CP was set up by simply reducing the arterial flow to a 
TABLE 3. Surgical procedures

\begin{tabular}{lc}
\hline Procedure & No. \\
\hline Procedures requiring carotid cannulation & \\
Hemiarch/open anastomosis & 57 \\
Total/subtotal arch repair* & 39 \\
Ascending arteriosclerosis & 4 \\
Concomitant procedures & \\
Composite valve graft & 49 \\
Valve-sparing root repair & 32 \\
Coronary artery bypass grafting & 22 \\
Aortic valve replacement & 10 \\
Mitral valve repair/replacement & 6 \\
Tricuspidal valve repair & 2 \\
\hline
\end{tabular}

*Including 4 elephant trunks and 4 proximal descending replacements.

mean flow of $0.85 \pm 0.2 \mathrm{~L} / \mathrm{min}$ in moderate hypothermia with a mean rectal temperature of $28.0^{\circ} \mathrm{C} \pm 1.5^{\circ} \mathrm{C}$. By modulation of the flow, average pressure in the arterial line was maintained at about $100 \mathrm{~mm} \mathrm{Hg}$, resulting in a mean pressure of $37.0 \pm 10.2 \mathrm{~mm} \mathrm{Hg}$ and $33.5 \pm 9.8 \mathrm{~mm} \mathrm{Hg}$ in the right and left radial arteries, respectively. The drop in flow velocity in the right middle cerebral artery varied considerably, but the flow never ceased. We administered thiopental for additional pharmacologic brain protection; thus, topical cooling of the head (apart from a few patients at the beginning of the study) was not performed. Acid-base balance was managed by the $\alpha$-stat method. The arterial line included a Y-shaped cannula, which can be used to perfuse the other brain hemisphere for realization of bilateral CP during circulatory arrest, if necessary. Nevertheless, we never had to make use of this additional CP. After the distal aortic anastomosis had been completed, and in total or subtotal arch replacements after reimplantation of the arch arteries, this Y-shaped cannula can also be used to switch the arterial perfusion from the carotid artery to an aortic graft. Because this manipulation is neither complicated nor time-consuming, we used it in all 75 patients in whom aortic grafts with side branches ("InterGard Hemabridge" with one side branch or "InterGard Aortic Arch" with four side branches; InterVascular, La Ciotat, France) were used. It leads to omission of reperfusion through the carotid artery during rewarming and shortens the overall perfusion time through the carotid artery. The vascular graft initially anastomosed with the common carotid artery was severed near the anastomosis and oversewn during reperfusion or after terminating CPB.

The most frequent surgical procedure was ascending aortic replacement with an open distal anastomosis to the aortic arch (hemiarch) followed by total or subtotal aortic arch replacement. The surgical procedures are shown in Table 3 and the operative data in Table 4.
TABLE 4. Operative data

\begin{tabular}{lc}
\hline $\begin{array}{l}\text { Median sternotomy (including } 1 \text { left lateral } \\
\quad \text { extension) }\end{array}$ & 96 \\
Clamshell thoracotomy & 4 \\
Unilateral cerebral perfusion (circulatory & 98 \\
$\quad$ arrest) & \\
Flow (L/min) & $0.9 \pm 0.2$ \\
Duration (min) & $25 \pm 18$ \\
& $(2-105)$ \\
Lowest rectal temperature $\left({ }^{\circ} \mathrm{C}\right)$ & $28 \pm 1.6$ \\
CPB flow (L/min) & $4.6 \pm 0.5$ \\
CPB time (min) & $187 \pm 54$ \\
Aortic crossclamp time including circulatory & $110 \pm 32$ \\
$\quad$ arrest (min) &
\end{tabular}

Data are expressed as number of occurrences or as median number \pm SD (range).

\section{Results}

Carotid artery cannulation provided adequate arterial return in all patients, especially in those who underwent single carotid cannulation. In no case was a switch to another cannulation site necessary for arterial return. Furthermore, we observed no complications related to the cannulation site.

There were 2 deaths during the 30 days after surgery. One patient (male, 47 years) with acute type A aortic dissection and preoperative multiorgan malperfusion died of peritonitis as a result of ischemic colon perforation despite surgical intervention on the 14th day after complete ascending and arch replacement, making the early mortality in the dissection group $3.7 \%$.

The other patient (male, 79 years) with chronic atherosclerotic aneurysm and aortic valve insufficiency died suddenly on the seventh day after valve-sparing ascending aortic and complete arch replacement caused by malignant arrhythmia resulting in cardiac arrest after an uneventful postoperative course. At autopsy, no pathologic conditions were found apart from severe left ventricular hypertrophy.

All patients regained consciousness postoperatively. Eight patients required prolonged primary postoperative ventilation, and 15 patients had to be reintubated owing to respiratory insufficiency, the most frequent postoperative complication. Eleven patients required tracheotomy (4 after prolonged primary ventilation and 7 after reintubation). Among those patients with pulmonary complications, there were 3 deaths that occurred in hospital, but after the 30-day time range; they were due to multiple organ failure or sepsis. Because none of these patients had acute aortic dissection, the in-hospital mortality remained $3.7 \%$ in that group.

The neurologic morbidity, that is, permanent or temporary focal deficit, was $2 \%$ for the overall series and none for the dissection group, although there were preoperative signs 
of cerebral malperfusion in 4 patients. One patient had a major stroke with right-sided hemiparesis and another patient had a minor stroke with complete resolution of neurologic symptoms within 30 days postoperatively. Both patients had undergone hemiarch replacement with brief unilateral CP (9 and 10 minutes, respectively). However, both patients had severe calcification of the aortic valve and aortic annulus, which had to be decalcified during replacement. We assume that this explains the postoperative CT evidence of intracranial embolization in both patients. Correlating with the mild clinical symptoms, the embolization was very discrete in the second patient. Moreover, 14 patients who were not extubated within 24 postoperative hours underwent a cranial CT. There were no pathologic findings in any of them.

\section{Discussion}

Cannulation of the femoral artery for open aortic arch repair remains a standard surgical technique in acute type A aortic dissection and chronic aneurysm. The technique permits fast, easy, low-risk installation of CPB..$^{1,3}$ There are, however, situations in which femoral artery cannulation is not possible or should be avoided; for example, in dissections extending to the iliac or femoral arteries or in severe atherosclerosis of these vessels. Furthermore, femoral artery cannulation in open aortic arch surgery is always associated with the necessity of circulatory arrest in deep hypothermia. Even though selective CP for brain protection is carried out, cerebral flow must be interrupted during placement of the perfusion cannulas in the supra-aortic vessels. During this manipulation, cerebrovascular injury may occur as a result of air embolism or the dislodgment of atherosclerotic debris. In acute dissection of arch vessels, direct cannulation with perfusion catheters can also damage the fragile vascular wall, resulting in bleeding complications or malperfusion. This may explain why neurologic complications in patients with selective antegrade CP could not be dramatically reduced when compared with deep hypothermia without selective $\mathrm{CP}$, especially if the circulatory arrest period is not too long. ${ }^{10,11}$

In contrast, in unilateral $\mathrm{CP}$ with cannulation of one of the arch arteries, neither interruption in CP nor manipulation of the arch arteries for perfusion cannula placement is necessary. After crossclamping of arch arteries, unilateral $\mathrm{CP}$ is maintained by simply reducing the flow in the arterial line. Because cerebral oxygen consumption drops to about $50 \%$ during moderate hypothermia, ${ }^{12}$ unilateral CP under this condition usually provides adequate brain protection resulting in very good neurologic outcome, as verified in recent clinical studies. ${ }^{8,9,13-15}$ Some authors have proposed filtering out those patients in whom unilateral $\mathrm{CP}$ might not suffice to adequately protect the brain, suggesting several preoperative diagnostics and intraoperative neurophysio- logic monitoring. ${ }^{16,17}$ Yet, the importance of these tests in clinical use remains undetermined. On the basis of our initial experience, we have recommended various tests for routine use in elective patients, but there are limitations that should be addressed. Most preoperative tests only provide anatomic information about the vessels supplying the brain. Nevertheless, Doppler ultrasonography of extracranial arteries should be the basis for choosing the proper cannulation site, even though in our series it proved effective in only 1 patient whose right carotid artery had to be cannulated. The role of cranial CT angiography remains unclear, as there is scant difference between normal and hypoplastic posterior communicating arteries. The intention of such examinations could be to detect extremely uncommon incompleteness of the arterial circle in both the anterior and posterior regions. We did not carry out carotid compression tests to functionally evaluate cerebral crossover perfusion in this study, as proposed by others, ${ }^{16,17}$ because the same information can be obtained during carotid crossclamping for cannulation. Electroencephalograms, somatosensory evoked potentials, and transcranial Doppler were used to monitor carotid artery crossclamp intolerance, which did not occur in any of our patients examined. Transcranial Doppler ultrasonography for evaluating intracranial flow is not always possible because of the absence of ultrasound windows. ${ }^{17,18}$ It is also unclear, even in normothermia, how great a drop in blood flow velocity in the middle cerebral artery is clinically significant. ${ }^{18}$ We have accepted even very low flow during unilateral $\mathrm{CP}$ in moderate hypothermia, but a complete stop did not occur in any patient. We consider the arterial pressure measurements in both radial arteries, and especially contralaterally to the cannulated carotid artery, as very reliable, although only as indirect parameters for monitoring the crossover flow during unilateral $\mathrm{CP}$. They can serve as a substitute for the surgeon's estimation of returning blood, as proposed by Kücüker and associates, ${ }^{14}$ which is a subjective value in any case. The pressure measurement is feasible in almost all patients and in emergencies. However, for this assessment, proximal crossclamping of all arch arteries, including the left subclavian artery, is necessary. On the basis of the findings mentioned above, we have not observed any patients in whom it was necessary to additionally perfuse the contralateral arch artery.

Numerous experiences with cannulation of the right axillary or brachial artery for arterial return have been reported recently. ${ }^{4,5,14,19}$ This access has also been used for unilateral CP during circulatory arrest. ${ }^{13-15}$ Yet, the surgical approach is time-consuming, especially in obese patients. Local complications with a rate of up to $14 \%$ and even dissections of the arterial system with lethal outcome have been reported. ${ }^{20-22}$ Owing to axillary walls of thin caliber or particular fragility, a switch to other cannulation sites is necessary in up to $11 \%$ of cases. ${ }^{22}$ 
Conversely, the common carotid artery wall is not as delicate or as easily damaged. In our series, we observed no local vessel alterations, and no switch to another cannulation site was necessary in any patient. The arterial return was sufficient in each case with isolated cannulation of the carotid artery. The 14 additional femoral cannulations in our series were mainly performed because of underlying pathologic conditions alone. Furthermore, the common carotid artery is easily accessible in the neck, and when appropriate, the left carotid artery can even be approached intrathoracically without an additional incision. For this reason, cannulation of the left carotid artery has become our routine; however, cannulation of the right carotid artery can provide additional antegrade perfusion of the right vertebral artery during CP. In turn, there is the potential risk of cerebral "luxury perfusion" during $\mathrm{CPB}$. Our strategy to prevent this overperfusion is to reduce the arterial pressure during $\mathrm{CPB}$ to about 50 to $60 \mathrm{~mm} \mathrm{Hg}$, because cerebral blood flow is determined mainly by the arterial pressure and not the CPB flow rate. ${ }^{23}$ Unilateral $\mathrm{CP}$ was performed with a mean pressure of about $100 \mathrm{~mm} \mathrm{Hg}$ in the arterial line, which corresponds to 50 to $60 \mathrm{~mm} \mathrm{Hg}$ of pressure in the carotid artery at a flow rate of about $1.0 \mathrm{~L} / \mathrm{min}$. Thus, we noted no symptoms of cerebral overperfusion in our series. Our neurologic results correlate equally well with the cranial CT findings from 14 patients after surgery in whom no disease was found, in particular, no signs of cerebral edema.

In conclusion, carotid artery cannulation makes simple installation of CPB possible with antegrade flow. The approach is safe, efficient, and quick in its execution and, therefore, suitable in emergencies and in obese patients. Carotid artery cannulation simplifies the unilateral $\mathrm{CP}$ procedure through the arterial line during circulatory arrest, meaning that there is no need to interrupt $\mathrm{CP}$, thus minimizing the risk of embolism and preventing the drawbacks associated with deep hypothermia.

\section{References}

1. Lakew F, Pasek P, Zacher M, Diegeler A, Urbanski PP. Femoral versus aortic cannulation for surgery of chronic ascending aortic aneurysm. Ann Thorac Surg. 2005;80:84-9.

2. Fusco DS, Shaw RK, Tranqulli M, Kopf GS, Elefteriades JA. Femoral cannulation is safe for type A dissection repair. Ann Thorac Surg. 2004;78:1285-9.

3. Kouchoukos NT, Masetti P, Rokkas CK, Murphy SF. Hypothermic cardiopulmonary bypass and circulatory arrest for operations on the descending thoracic and thoracoabdominal aorta. Ann Thorac Surg. 2002;74:S1885-7.

4. Sabik JF, Nemeh H, Lytle BW, Blackstone EH, Gillinov AM, Rajeswaran J, et al. Cannulation of the axillary artery with a side graft reduces morbidity. Ann Thorac Surg. 2004;77:1315-20.

5. Numata S, Ogino H, Sasaki H, Hanafusa Y, Hirata M, Ando M, et al. Total arch replacement using antegrade selective cerebral perfusion with right axillary artery perfusion. Eur J Cardiothorac Surg. 2003; 23:771-5.

6. Frist WH, Baldwin JC, Starnes VA, Stinson EB, Oyer PE, Miller DC, et al. A reconsideration of cerebral perfusion in aortic arch replacement. Ann Thorac Surg. 1986;42:273-81.
7. Neri E, Massetti M, Barabesi L, Pula G, Tassi R, Toscano T, et al. Extrathoracic cannulation of the left common carotid artery in thoracic aorta operations through a left thoracotomy: preliminary experience in 26 patients. J Thorac Cardiovasc Surg. 2002;123:901-10.

8. Urbanski PP. Cannulation of the left common carotid artery for proximal aortic repair. J Thorac Cardiovasc Surg. 2003;126:887-8.

9. Urbanski PP. Carotid artery cannulation in acute aortic dissection with malperfusion. J Thorac Cardiovasc Surg. 2006;131:1398-9.

10. Ueda T, Shimizu H, Ito T, Kashima I, Hashizume K, Iino Y, et al. Cerebral complications associated with selective perfusion of the arch vessels. Ann Thorac Surg. 2000;70:1472-7.

11. Di Eusanio M, Wesselink RMJ, Morshuis WJ, Dossche KM, Schepens MAAM. Deep hypothermic circulatory arrest and antegrade selective cerebral perfusion during ascending aorta-hemiarch replacement: a retrospective comparative study. J Thorac Cardiovasc Surg. 2003;125: 849-54.

12. Ehrlich MP, McCullough JN, Zhang N, Weisz DJ, Juvonen T, Bodian CA, et al. Effect of hypothermia on cerebral blood flow and metabolism in the pig. Ann Thorac Surg. 2002;73:191-7.

13. Aebert H, Reber D, Kobuch R, Philipp A, Birnbaum DE. Aortic arch surgery using moderate systemic hypothermia and antegrade cerebral perfusion via the right subclavian artery. Thorac Cardiovasc Surg. 2001;49:283-6.

14. Kücüker SA, Özatik MA, Saritas A, Tasdemir O. Arch repair with unilateral antegrade cerebral perfusion. Eur J Cardiothorac Surg. 2005: 27:638-43.

15. Zierer A, Aybek T, Risteski P, Dogan S, Wimmer-Greinecker G, Moritz A. Moderate hypothermia $\left(30^{\circ} \mathrm{C}\right)$ for surgery of acute type a aortic dissection. Thorac Cardiovasc Surg. 2005;53:74-9.

16. Di Eusanio M, Schepens MA, Morshuis WJ, Di Bartolomeo R, Pierangeli A, Dossche KM. Antegrade selective cerebral perfusion during operations on the thoracic aorta: factors influencing survival and neurologic outcome in 413 patients. $J$ Thorac Cardiovasc Surg. 2002;124:1080-6.

17. Karadeniz Ü, Erdemli Ö, Özatik MA, Yamak B, Demirci A, Kücüker SA, et al. Assessment of cerebral blood flow with transcranial Doppler in right brachial artery perfusion patients. Ann Thorac Surg. 2005;79: $139-46$.

18. Lacroix H, Beyens G, Van Hemelrijck J, Nevelsteen A, Verhaeghe R, Suy R. Is transcranial Doppler useful in the detection of internal carotid artery cross-clamp intolerance? Cardiovasc Surg. 1999;7:203-7.

19. Strauch JT, Spielvogel D, Lauten A, Lansman SL, McMurtry K, Bodian CA, et al. Axillary artery cannulation: routine use in ascending aorta and aortic arch replacement. Ann Thorac Surg.2004;78:103-8.

20. Imanaka K, Kyo S, Tanabe H, Ohnchi H, Asano H, Yokote Y. Fatal intraoperative dissection of the innominate artery due to perfusion through the right axillary artery. J Thorac Cardiovasc Surg. 2000;120: 405-6.

21. Miyatake T, Matsui Y, Suto Y, Imamura M, Shiiya N, Murashita T, et al. A case of intraoperative aortic dissection caused by cannulation into an axillary artery. J Cardiovasc Surg (Torino). 2001;42:809-11.

22. Schachner T, Nagiller J, Zimmer A, Laufer G, Bonatti J. Technical problems and complications of axillary artery cannulation. Eur J Cardiothorac Surg. 2005;27:634-7.

23. Schwartz AE, Sandhu AA, Kaplon RJ, Young WL, Jonassen AE, Adams DC, et al. Cerebral blood flow is determined by arterial pressure and not cardiopulmonary bypass flow rate. Ann Thorac Surg. 1995;60:165-9.

\section{Discussion}

Dr R. Scott Mitchell (Stanford, Calif). Dr Diegler and his colleagues are to be congratulated on a very beautiful presentation and good results in a complex set of patients; 30-day mortality was $2.2 \%$, with strokes noted in only 2 patients. This demonstrates, at least in this series, the adequacy of unilateral CP monitored by bilateral radial artery pressure monitoring at flow rates of only 800 $\mathrm{mL} / \mathrm{min}$. Circulatory arrest times were admittedly short, with a mean time of only 26 minutes and at a temperature of $28^{\circ} \mathrm{C}$. I have just a few questions. 
First, were these 100 consecutive patients and, if not, how were they selected? Second, did you encounter any dissected carotid arteries and, if so, how were those managed? Third, you note that there are only 2 patients with focal neurologic deficits postoperatively. Did you note any patients with more generalized temporary neurologic dysfunction? Last, was the right radial pressure the only means of monitoring adequacy of $\mathrm{CP}$ ?

Dr Diegeler. Thank you, very much, Dr. Mitchell, for the excellent comments and the questions. Regarding the first question, the population does not include consecutive patients only. The patients became consecutive after January 2005. We started using this procedure in 2002 in a patient with a particular surgical condition. Because the approach went well and looked easy, we used it in some selected patients afterward. This selection within the first period was more related to very diseased patients or emergency patients. The first group of patients rather reflects a more sick patient population. Since we became more and more familiar with the approach, we use it now for every single patient.

Regarding the second question: Yes, we had 1 patient with a dissected carotid artery and in this patient our approach offered some advantages because we could address the dissection. We crossclamped the segment and performed an end-to-end anastomosis with the graft used for the perfusion line. There was 1 other patient with obstructive carotid disease in whom we used an additional femoral line, and of course we started the perfusion via the femoral artery retrogradely.

Third, you inquired about the role of radial artery pressure monitoring. We have the impression that right and left radial artery pressure monitoring can indicate cross-perfusion, but the supraaortic artery has to be occluded during selective perfusion. For example, if you open the left subclavian artery, this pressure should drop to zero, and if you occlude it again, then it should rise again. You could test it with the contralateral side as well. I do not know what value this measurement has, but we feel a little bit safer with this maneuver if it is possible to work out.

Regarding temporary neurologic dysfunction, this is a population of very sick patients. Some of the patients had prolonged ventilation times. In those, it is very difficult to do sophisticated neurologic tests such as neurocognitive function. We could not detect a transient focal neurologic deficit in all of our patients, but of course we could miss some.

Dr Mitchell. Just one last question. After merely oversewing the stump of the graft, did you see any late neurologic events related to that left carotid?

Dr Diegeler. No. We just cut the graft down to its basis and performed a 2-layer suture. So far, we have not seen any throm- boembolic problems. We have a follow-up of at least 30 days or 6 weeks after surgery, because most of our patients are discharged to our local rehabilitation center, and if a patient would have such a problem, he would be sent back to our hospital. We are very sure that there is no embolic event, at least during the early period after surgery.

Dr Tirone E. David (Toronto, Ontario, Canada). Dr Diegeler, I am a bit puzzled why you chose the left carotid instead of the right axillary artery. If you perfuse the axillary artery, you provide not only the carotid but also the right vertebral. So the chance for a better cross-circulation is almost doubled, and yet you picked the left carotid. What is the rationale to change from the right axillary artery to the left carotid?

Dr Diegeler. That is a very good question and you are right on that point. The left carotid is a very easy approach and we want to have it easy. To be honest, we had 1 patient with an absent left vertebral artery, and in this patient we used the right carotid artery and clamped the brachiocephalic trunk just above the aortic arch to provide additional flow through the right vertebral artery. However, if the brachiocephalic trunk is diseased, it should not be crossclamped. I do not think this situation makes a big difference. But in general, you are right on that point.

Dr David. It has been my experience that if we maintain the systemic temperature at $25^{\circ} \mathrm{C}$, we have to pump more than a liter per minute to maintain a mean pressure of 50 or $60 \mathrm{~mm} \mathrm{Hg}$. I noticed your flow is only $0.9 \mathrm{~L} / \mathrm{min}$. What was the pressure in the radial artery?

Dr Diegeler. The mean pressure in the radial artery was around $30 \mathrm{~mm} \mathrm{Hg}$. The difference between the right and left sides was about $10 \mathrm{~mm} \mathrm{Hg}$. We followed the literature. The literature has mentioned a flow of 10 or $15 \mathrm{~mL} / \mathrm{kg}$ weight. We increased it a bit. Usually we had $1000 \mathrm{~mL}$, sometimes 1,200, but the mean was 800 .

Dr Thoralf Sundt (Rochester, Minn). Maybe I missed this, but I am concerned about ipsilateral hyperperfusion. Did you put a needle in the carotid distal to the graft and measure the relative pressures in the body and in the distal carotid?

Dr Diegeler. This is a very important point. We do not have a pressure measurement distal to the graft. In a couple of cases, just to know what happens, we used an 8- or 10-mm Doppler probe for flow measurement. We estimate about $800 \mathrm{~mL}$ forward volume in the situation when we had a total of $5.5 \mathrm{~L}$ backward body perfusion, as you may have seen in the second or third slide. In some of our first patients who were not awakened the next day, we performed a CT scan the next day, and we never could detect signs of ipsilateral edema on the perfusion side. But you are right; you never can exclude an overflow on the ipsilateral side of the brain. 